\title{
LA.UR- 923 \\ Title: \\ Structural Determination of Larger Proteins Using Stable Isotope Labeling and NMR Spectroscopy
}

Author(s):

Clifford Unkefer, CST-4

Donald Blumenthal, University of Utah

RECEIVED

Griselda Hernandez, CST-4

Mary Lidstrom, California Institute of Technology

Penelope Springer, CST-4

Jill Trewhella, CST-4

Submitted to:

DISCLAIMER

\section{DOE Office of Scientific and Technical Information (OSTI)}

This report was prepared as an account of work sponsored by an agency of the United States Government. Neither the United States Government nor any agency thereof, nor any of their employees, makes any warranty, express or implied, or assumes any legal liability or responsibility for the accuracy, completeness, or usefulness of any information, apparatus, product, or process disclosed, or represents that its use would not infringe privately owned rights. Reference herein to any specific commercial product, process, or service by trade name, trademark, manufacturer, or otherwise does not necessarily constitute or imply its endorsement, recommendation, or favoring by the United States Government or any agency thereof. The views and opinions of authors expressed herein do not necessarily state or reflect those of the United States Government or any agency thereof.

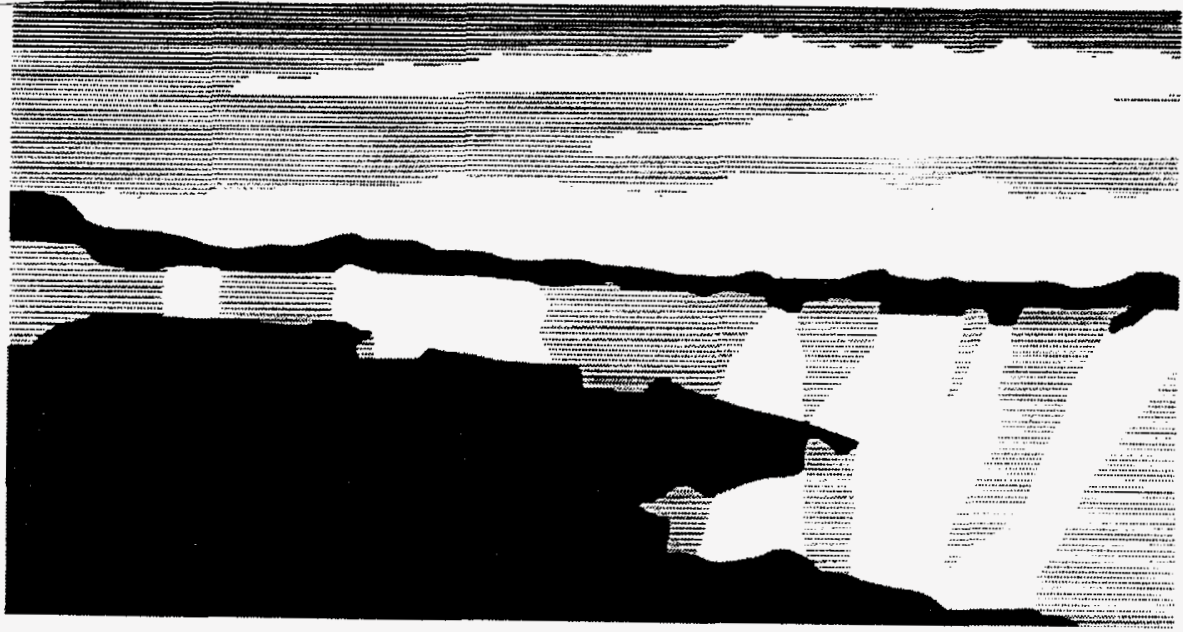

Los Alamos National Laboratory, an aftirmative action/equal opportunity employer, is operated by the University of California for the U.S. Department of Energy under contract W-7405-ENG-36. By acceptance of this article, the publisher recognizes that the U.S. Government relains a nonexclusive, royaltytree license to publish or reproduce the published form of this contribution, or to allow others to do so, 1or U.S. Government purposes. The Los Alamos National Laboratory requests that the publister identify this article as work performed under the ayspices of the U.S. Department of Energy. 


\section{DISCLAIMER}

Portions of this document may be illegible in electronic image products. Images are produced from the best available original document. 


\title{
Structural Determination of Larger Proteins Using \\ Stable Isotope Labeling and NMR Spectroscopy
}

\author{
Clifford Unkefer*, Donald Blumenthal (University of Utah), \\ Griselda Hernandez, Mary Lidstrom (California Institute of Technology), \\ Penelope Springer, and Jill Trewhella
}

\begin{abstract}
This is the final report of a three-year, Laboratory-Directed Research and Development (LDRD) project at the Los Alamos National Laboratory (LANL). The project sought to employ stable isotope labeling and NMR spectroscopy to study protein structures and provide insight into important biochemical problems. A methylotrophic bacterial expression system has been developed for uniform deuterium and carbon-13 labeling of proteins for structural studies. These organisms grow using methanol as the sole source of carbon and energy. Because isotopically labeled methanol is relatively inexpensive, the methylotrophs are ideal for expressing proteins labeled uniformly with deuterium and/or carbon-13. This expression system has been employed to prepare deuterated troponin C. NMR spectroscopy measurements have been made on the inhibitory peptide from troponin I (residues 96-115), both as the free peptide and the peptide complexed with deuterated troponin C. ProtonNMR spectroscopy resonance-signal assignments have been made for the free peptide.
\end{abstract}

\section{Background and Research Objectives}

Nuclear magnetic resonance (NMR) spectroscopy has emerged as a powerful technique in high-resolution biomolecular-structure determination. Because NMR methods probe structures of molecules in solution, they can be used to study the structure of molecular complexes that form in solution but are recalcitrant to the crystallization required for conventional X-ray crystallography. Determination of structures of biological macromolecules by NMR spectroscopy relies on the proton-proton distances derived from the nuclear Overhauser effect (NOE) and on dihedral angles determined from spin-spin coupling

\footnotetext{
* Principal investigator, e-mail: cju@lanl.gov
} 
interactions. Standard two-dimensional, nuclear Overhauser effect spectroscopy (NOESY) and correlation spectroscopy (COSY) ${ }^{1} \mathrm{H}-\mathrm{NMR}$ methods are now used routinely to determine the solution structures of relatively small proteins (molecular weights less than $15 \mathrm{KDa}$ ). To be successful, this approach requires the one-to-one assignment of each resonance in the NMR spectrum to a particular proton in the protein. Because both the proton-resonance line width and the number of protons increase in proportion with the molecular weight of the protein, severe spectral overlap occurs at higher molecular weights introducing a practical limitation to this approach. This limitation is partially overcome in several ways. First, high-resolution NMR spectrometers are being built with higher magnetic fields, which increase the spectral resolution. In addition, three-dimensional (3D) and four-dimensional (4D) NMR methods have been developed that minimize spectral overlap problems. In this approach, the proton resonances are spread out on a carbon-13 and/or nitrogen- 15 chemical shift axis. For sensitivity reasons, 3D and 4D NMR methods require the production of uniformly ${ }^{13} \mathrm{C}$ - and $15 \mathrm{~N}$-enriched proteins and are limited by the relatively difficult and expensive methods used for ${ }^{13} \mathrm{C}$ labeling of proteins. Finally, substitution of deuterium for protons in a biological macromolecule effectively increases the spectral resolution in two ways. First, deuteration can be used to eliminate resonances from the spectrum that contribute to spectral crowding but yield little structural information. Second, deuterium substitution can eliminate the proton-proton dipolar interactions that contribute significantly to the line-width broadening and effectively sharpen the resonance signals from the remaining protons.

Our overall goal is to use stable-isotope labeling and very high field NMR spectroscopy to determine the structures of large protein complexes. First, we are examining cytochrome $\mathrm{cL}$, which is part of a relatively simple electron transport chain used for energy transduction in the methylotrophic bacteria. These organisms grow using methanol as the sole source of carbon and energy. We have used this property to enrich cytochrome cL with carbon-13 and have generalized this approach to labeling proteins by developing an expression system for methylotrophs. In addition, we are examining the structure of the calmodulin ( $\mathrm{CaM}$ ) complexed with its binding domain from phosphorylase kinase (PhK). The detailed structures provided by the NMR approaches described here will provide insight into the detailed molecular interactions between $\mathrm{CaM}$ and $\mathrm{PhK}$ in the regulatory complex. The combination of higher field NMR spectroscopy and isotopic labeling to deduce the high-resolution solution structures of relatively larger proteins, cytochrome cL (molecular weight approximately 21 $\mathrm{KDa}$ ) and the somewhat larger complex of $\mathrm{CaM}$ with the $\mathrm{CaM}$-binding domain of $\mathrm{PhK}$ (molecular weight approximately $24 \mathrm{KDa}$ ) will push the limits of the current technical capabilities in structural NMR to larger protein structures. 
The goal of this LDRD project was to provide preliminary results that demonstrate the validity of the approach. These results should demonstrate (1) systems for the expression labeled proteins; (2) the ability to obtain useful 3D COSY and NOESY spectra; (3) the ability to make a significant fraction of the chemical shift assignments in labelled proteins; and (4) the observation of long-range NOEs required for structural determination. We have demonstrated all of these capabilities. We have developed a bacterial expression system for uniform labeling of proteins with ${ }^{2} \mathrm{H}$ and ${ }^{13} \mathrm{C}$. We have demonstrated expression of mammalian proteins in methylotrophic bacteria using isotopically labeled methanol as the sole source of carbon and energy. Because isotopically labeled methanol is relatively inexpensive, the methylotrophs are ideal for expressing proteins labeled uniformly with ${ }^{2} \mathrm{H}$ and/or ${ }^{13} \mathrm{C}$. As discussed below, fully deuterated troponin $\mathrm{C}$ was used to greatly simplify the spectra of the troponin $\mathrm{C} /$ troponin $\mathrm{I}$ complex enabling us to make the complete chemical shifts assignment and draw preliminary conclusions about the structure of troponin I in the complex

\section{Importance to LANL's Science and Technology Base and National R\&D Needs}

The Department of Energy's Office of Health and Environmental Research (DOE/OHER) has instituted a major initiative in structural biology. The initative seeks to build up the unique facilities of the national laboratories as structural biology centers for external and internal users and to strengthen the in-house structural biology research programs to address the missions of the DOE. Stated missions are the structural problems associated with the Human Genome Project, DNA damage and repair, and the application of unique capabilities to important biological problems. This work enhances LANL's ability to respond to this OHER initiative. This work complements ongoing LANL programs in carbon metabolism of methylotrophic bacteria, signalling mechanisms and calcium regulation using small-angle scattering, and the National Stable Isotopes Resource at Los Alamos.

\section{Scientific Approach and Results}

Muscle contraction is regulated by a calcium-dependent molecular switch that involves an interaction of troponin with actin. At low calcium concentrations, troponin I (TnI) binds to troponin $\mathrm{C}(\mathrm{TnC})$ and inhibits its interaction with actin. By examining the structure of the troponin $\mathrm{C} /$ troponin $\mathrm{I}$ in the complex, we are attempting to understand the molecular mechanism by which this switch functions. The complex of $\mathrm{TnC}$ and $\mathrm{TnI}$ is too large to study by NMR methods. However, a peptide (the inhibitory peptide), made of the sequence of 
amino acids 96-115 of troponin I, is known to bind to $\mathrm{TnC}$ and inhibit its interaction with actin. We have used NMR spectroscopy to examine the inhibitory peptide derived from TnI, both free in solution and bound to TnC. We have obtained useful multidimensional NMR spectra and made the sequential chemical shift assignments.

Samples were prepared of the TnI inhibitory peptide, both alone and in a molecular complex with $\mathrm{TnC}$ that was fully deuterated. In order to establish that the peptide was bound to $\mathrm{TnC}$, transverse relaxation times (T2) for the free peptide and the peptide complexed with TnC were determined at $35^{\circ} \mathrm{C}$ using the spin-echo technique. Data were obtained using pulse delays between 50 to $200 \mathrm{~ms}$ for side chain protons, and 40-160 ms for aromatic and amide protons. As expected, the peptide that complexed with $\mathrm{TnC}$ had significantly shorter $\mathrm{T} 2$ than those observed for the free peptide.

Proton resonance assignments were made for the twenty-amino-acid peptide from TnI (96-115) at $5^{\circ} \mathrm{C}$ and $\mathrm{pH} 5.5$ using two-dimensional total correlation spectroscopy (2DTOCSY). Resonance signals from eighteen of the twenty amino acids were assigned; the other two were tentatively assigned. The resonance assignments are tabulated on the following page. The complete sequential assignment was difficult, because of the large number of arginine (four), leucine (three) and lysine residues (three). The presence of six $\mathrm{N}-\mathrm{H}$ to $\mathrm{N}-\mathrm{H}$ crosspeaks and six alpha- $\mathrm{H}$ to $\mathrm{N}-\mathrm{H}$ crosspeaks suggest a nascent helix or at least a few turns. Comparison of the chemical shifts, following the empirical rule of Wishart [1], also agrees with some helix formation.

The low solubility of samples of inhibitory peptide from TnI complexed with deuterated TnC made NMR analysis of the complex difficult. The complex was soluble only to the extent of $0.7 \mathrm{mM}$ in the presence of 1 percent trifloroethanol. At this low concentration, it was difficult to observe crosspeaks in spectra obtained at $500 \mathrm{MHz}$. This sensitivity problem was overcome by obtaining spectra at $750 \mathrm{MHz}$. By obtaining spectra at several $\mathrm{pH}$ values, the sequential assignment for the bound peptide has recently been completed. As with the free peptide, the presence of alpha-H to $\mathrm{N}-\mathrm{H}$ crosspeaks suggest helix formation.

\section{Reference}

1. D.S. Wishart, et al., Biochemistry , 31, 1647-1651, 1992. 
ASSIGNMENTS OF FREE PEPTIDE TnI (96-115) at 5०C

Arginine

Residue\#

115

113

8.572

$\alpha$
4.22

$1.788,1.735$

$1.625,1.576$

$\delta$

NH

112

4.3

$1.744,1.704$

$1.594,1.537$

3.160

7.22

7.204

103

8.458

4.28

$1.748,1.70$

$1.594,1.528$

3.147

$$
7.402
$$

108

8.423

4.2

$1.840,1.801$

$1.642,1.603$

3.147

3.143

4.46

$1.788,1.788$

$1.660,1.660$

3.170

Glutamate 7.226

Residue\# 97

Phenylalanine
8.6
$\stackrel{\alpha}{4.247}$
$2.052,1.95$

$\begin{array}{ccc}\text { NH } & \alpha & \beta \\ 8.216 & 4.559 & 3.08,2.960 \\ 8.189 & 4.507 & 3.05,2.967\end{array}$

2.32

Residue\#

106

100

Lysine

Residue\#

98

107

105

Leucine

Residue\#

111

102

99

Valine

Residue\# 114

Serine

Residue\# 96

Aspartate

Residue\# 101

\section{Glycine}

Residue\#

Proline

Residue\#

109

110

\begin{tabular}{lc}
\multicolumn{1}{c}{$\mathrm{NH}$} & $\alpha$ \\
8.334 & 4.185 \\
8.198 & 4.212 \\
8.123 & 4.168 \\
2.8974 & 7.547
\end{tabular}

$\beta$
1.678
1.686
1.616

$\stackrel{\gamma}{\gamma}$ 1.370, 1.308

$\delta$
1.616
1.612
1.546

1.317

$1.229,1.172$

\subsection{4}

$\mathrm{NH}$

7.56

7.55

\begin{tabular}{ccccr} 
NH & $\alpha$ & $\beta$ & $\gamma$ & Me \\
8.405, & 4.225 & 1.515 & 1.568 & 0.833 \\
8.321 & 4.216 & 1.638 & & 0.908 \\
8.137 & 4.221 & 1.530 & & 0.850 \\
& & & \multicolumn{2}{c}{ Methyl Groups } \\
NH & $\alpha$ & $\beta$ & \multicolumn{2}{c}{0.89}
\end{tabular}

Methyl Groups

$0.908,0.842$

$0.850,0.780$

Methyl Groups

NH $\quad \alpha \quad \beta$

$\begin{array}{lll}8.427 & 4.317 & 3.81\end{array}$

$\begin{array}{ccc}\mathrm{NH} & \alpha & \beta\end{array}$

$8.335 \quad 4.524 \quad 2.663,2.606$

NH $\alpha$

$8.291 \quad 3.842$

$\begin{array}{cccc}\alpha & \beta & \gamma & \delta \\ 4.639 & 2.320,1.836 & 1.999 & 3.811,3.6 \\ 4.361 & 2.223,1.818 & 1.95 & 3.737,3.565\end{array}$

